\title{
La balanza de la justicia: las lecciones jurídicas shakespearianas en Medida por medida
}

The Scales of Justice: The Shakespearean Juridical Lessons in Measure for Measure

\author{
Emilia JOCELYN-HOLT CORREA 2 \\ Universidad de Santiago de Chile \\ emilia.jocelyn-holt@usach.cl
}

\section{Resumen}

El siguiente artículo analiza Medida por Medida, una de las obras jurídicas de Shakespeare. Se propone que en ella el bardo nos presenta un caso difícil y un acabado estudio de tres posibles concepciones del derecho y la justicia, y la repercusión práctica que estas discusiones teóricas tienen en los individuos. Estas opciones están representadas en Ángelo, el supuesto ángel; la salida teatral del Duque; y Escalus, cuyo nombre nos recuerda la balanza de la justicia. A través de Ángelo vemos la aplicación estricta de la ley y la negación del rol judicial. En el caso del Duque se ilustra el exceso de misericordia que conlleva una negación del derecho y una apuesta por el teatro. La salida para Shakespeare se encontraría en Escalus, la balanza entre la letra de la ley y el espíritu del derecho, un respeto a la ley a la vez que una consideración de las circunstancias que llevan a aplicar equidad dentro del derecho.

Palabras clave: Derecho y literatura; William Shakespeare; Medida por Medida; concepto de derecho; justicia.

\footnotetext{
1 Agradezco especialmente los comentarios de Sofía Correa Sutil y Alexis Ramírez Donoso. Estoy segura que luego de sus valiosas sugerencias el texto mejoró de forma significativa. Este artículo fue escrito durante mis estudios doctorales (J.S.D. program) en la Facultad de Derecho, Universidad de Yale (Yale Law School), programa que ha sido financiado por el gobierno chileno a través de la Agencia Nacional de Investigación y Desarrollo (ANID) DOCTORADO BECAS CHILE/2019 - 72200304. Durante este programa también he recibido financiamiento de la Universidad de Santiago de Chile. Estoy agradecida de ambas instituciones que me han permitido realizar mis estudios doctorales.

2 Abogada, Licenciada en Ciencias Jurídicas y Sociales, Universidad de Chile, Magister en Derecho (LL.M.) 2019 Yale University, Candidata a Doctor por Yale University (J.S.D. Candidate) Yale University, Académica Facultad de Derecho, Universidad de Santiago de Chile, autora del libro Del caos al imperio del derecho. La búsqueda de la justicia en Shakespeare (Santiago: Rubicón, 2018). Co-editora junto a Joaquín Trujillo del libro Ficciones jurídicas. Derecho y literatura en Chile (Santiago: Rubicón, 2019).
}

La balanza de la justicia: las lecciones jurídicas shakespearianas en Medida por medida Sur y Tiempo. Revista de Historia de América, №5, enero-junio 2022, pp. 28-49. 


\begin{abstract}
This article analyzes Measure for Measure by William Shakespeare. It proposes that Shakespeare presents us with a hard case. The play allows us to study three possible conceptions of law and justice and the practical effects of choosing one over the other on individuals. Shakespeare illustrates these three alternatives through Angelo, the "angel", the theatrical solution of the Duke, and Escalus, whose name reminds us of the scales of justice. In Angelo, we see the strict application of law and the denial of the judicial role. The Duke illustrates the excess of mercy. The Duke also ends up denying law and betting for the theater instead. Shakespeare proposes that the solution is to be found in Escalus, who is able to balance the letter of the law and its spirit. While the law is respected, the different circumstances of the particular case are also considered. In this way, mercy is institutionalized into law through equity.
\end{abstract}

Keywords: Law and Literature; William Shakespeare; Measure for Measure; concept of law; justice.

\title{
1. Introducción
}

Luego de que, en sus tragedias, William Shakespeare nos haya mostrado el riesgo de tener un mundo sin derecho, en el cual solo queda la venganza como método de solución de conflictos (Jocelyn-Holt, 2017), en sus comedias nos presenta un universo en que la justicia se encuentra institucionalizada. Nos encontramos en el pleno imperio del derecho. Es en este contexto que Shakespeare se pregunta por la naturaleza del derecho y su relación con la justicia. También se interesa por los peligros que un sistema institucionalizado de adjudicación de justicia puede presentar. En este artículo se analizará una de sus obras más relevante en estas materias: Medida por Medida.

Medida por Medida es uno de esos textos shakesperianos que ha sido difícil de clasificar. Durante siglos, los críticos literarios han intentado, sin éxito, encasillarla en una u otra categoría. Para algunos, es una comedia, para otros, un romance. En general, ha sido considerada una obra problema. Así, Coleridge la encontraba una obra dolorosa (Bloom, 1998: 362), Swinburne propuso que era inclasificable y Croce señaló que no persuadía. R.W. Chambers la ha descrito como uno de los textos menos entendidos en la literatura inglesa (Keeton, 1968: 371-372). Quizás una de las interpretaciones más potentes es la de Harold Bloom, para quien esta obra es la despedida de Shakespeare a la comedia. Su texto y trama es tan nihilista que habría que entenderla como una comedia que destruye la comedia (Bloom, 1998: 358, 380).

Por otra parte, Medida por Medida junto con El Mercader de Venecia son consideradas las obras jurídicas de Shakespeare. Si bien encontramos desarrollados 
temas de justicia y de filosofía del derecho en prácticamente todas las obras del bardo, en las llamadas ‘obras jurídicas' el derecho se transforma en el tema principal. En ellas, Shakespeare ya no usa el derecho como metáfora sino que es el fundamento de la obra (Kornstein, 1994: 35). Así, por ejemplo, ha sido entendido el acto final de $E l$ Mercader de Venecia. El caso de Medida por Medida es algo distinto. La discusión sobre el derecho permea la obra completa, desde su primer acto hasta el último. Es en parte por esto que la obra ha sido considerada una pieza de filosofía jurídica, un estudio sobre el imperio del derecho en todas sus dimensiones (Visconsi, 2011: 280).

En ese contexto, para algunos críticos, Medida por Medida es la primera obra en que Shakespeare se decepciona del derecho como un método de resolución de conflictos (Goddard, 1960: 51). Este artículo no sigue dicha interpretación; al contrario, se propone que nuevamente en esta obra vemos la apuesta de Shakespeare por el derecho como una salida pacífica al conflicto. No hay una desilusión, sino que un acabado estudio de cuáles son las posibles formas de entender el derecho, su relación con la justicia y la repercusión que estas discusiones tienen en los individuos. De esta forma, Shakespeare nos ilustra en un caso concreto el impacto práctico que tiene concebir el derecho y la justicia de una u otra forma. Es un ejercicio similar al que hará posteriormente Lon Fuller en El Caso de los Exploradores de Cavernas (Fuller, 2002).

En este sentido, este artículo sigue la interpretación que se ha dado de Medida por Medida por una serie de shakesperianos. Así, por ejemplo, Keeton considera que en Ángelo y el Duque hay dos concepciones distintas de la justicia criminal (Keeton, 1968: 382). Kornstein, por su parte, señala que tanto en Ángelo como en la dupla Duque-Escalus habría dos conceptos de derecho (Kornstein, 1994: 58-61). Finalmente, Kenji Yoshino propone que en la obra vemos tres versiones de jueces y cada uno con una concepción propia de su rol. Estas estarían representadas por el Duque, que valora la empatía en demasía y termina erosionando el imperio del derecho, Ángelo, que es excesivamente estricto en la aplicación de la letra de la ley, y Escalus, que sería un punto medio entre ambos (Yoshino, 2011).

En este artículo se argumenta que en Medida por Medida no solo hay tres visiones del concepto de derecho, sino que además estas se concretizan en tres concepciones distintas de justicia. Shakespeare construye estos enfoques a través de distintas teorías sobre el rol judicial y la importancia de la interpretación. Para poder llevar a cabo este análisis, el artículo se desarrollará de la siguiente manera. En la próxima sección se explicarán los hechos del caso, cuál es la historia de Medida por Medida. Luego, se desarrollarán las tres visiones del derecho que nos presenta Shakespeare a través de sus personajes: Ángelo, el Duque y Escalus. 


\section{El caso}

¿Cuál es el caso en Medida por Medida? El telón abre en Viena, la ciudad carnavalesca en donde se ha perdido el respeto por el derecho. Nos enteramos que, si bien el reino tiene reglas sumamente estrictas, durante más de una década no han sido aplicadas. El Duque no sabe qué hacer, ya que sus constantes perdones y absoluciones han traído consigo todo tipo de desórdenes.

DUKE. We have strict statutes and most biting laws,

The needful bits and curbs to headstrong weeds,

Which for this fourteen years we have let slip,

Even like an o'ergrown lion in a cave

That goes not out to prey. Now, as fond fathers,

Having bound up the threatening twigs of birch,

Only to stick it in their children's sight For terror, not to use, in time the rod

More mocked than feared; so our decrees,

Dead to infliction, to themselves are dead,

And liberty plucks justice by the nose,

The baby beats the nurse, and quite athwart

Goes all decorum

(Act 1, scene 3, lines 19-31)

(Shakespeare, 2020, 181-182)
DUQUE. Nos regimos por estatutos estrictos y leyes muy incisivas.

Freno y rienda para someter potras alocadas que, lúbricas,

Hemos dejado abandonadas los últimos catorce años.

Cual degenerado león en su cueva, Que ya no persigue a su presa, Nos, padres indulgentes,

Hemos trenzado amenazadoras ramas de abedul,

Sólo para lucirlas ante las miradas de los hijos Y así infundirles terror, y no

para su uso; siendo con el tiempo la vara

Más burlada que temida... Esto mismo sucedió con nuestras leyes:

Muerto el uso, se quedaron muertas. De este modo el libertinaje agarra por la nariz a Justicia, El niño azota a Nodriza, y Decoro Camina a la deriva

(Acto 1, escena 4, líneas 19-31) (Shakespeare, 2015, 149-151)

Quizás la imagen más decidora es esta última: Viena se ha vuelto una ciudad en donde los niños le pegan a sus nodrizas. Nadie cumple la ley. Si bien es posible argumentar que el derecho requiere cierta transgresión para legitimar su imperio, el problema en Viena es que el incumplimiento es generalizado. El Duque se da cuenta que la consecuencia ha sido una pérdida de autoridad del sistema político. El carnaval abunda y es necesario recuperar el control. Sin embargo, el Duque no está dispuesto a hacer el trabajo sucio, pues cree que si ahora aplica las leyes que han estado dormidas durante tanto tiempo parecerá un tirano. Su solución será decir que abandonará la ciudad por una misión diplomática y dejar a dos de sus más cercanos colaboradores a cargo. Al mando queda Ángelo y como su segundo Escalus. La verdad 
es que el Duque no abandona Viena, sino que se disfraza de fraile y se oculta, para observar todo desde las sombras.

En este contexto, Ángelo utiliza el procedimiento judicial para instaurar un régimen moral basado en antiguas leyes que se encontraban dormidas. La mayoría de éstas regulan el ámbito sexual. Hay una serie de casos relacionados con prostíbulos, los cuales han sido todos cerrados por Ángelo. Sin embargo, el juez no se encuentra interesado en estos y se los deja todos a Escalus, quien tendrá que fallar todos aquellos casos que trae a su atención Elbow, el algo corrupto alguacil de Viena. Así, por ejemplo, llevará a Froth y Pompey, quienes incumplen la regulación al estar vinculados al prostíbulo de Mistress Overtone. Escalus siempre comienza con una advertencia, pero si se repiten los hechos aplicará la ley.

El caso más complicado y el que toma Ángelo en sus propias manos, es el de Claudio. Claudio habría dejado embarazada a Julieta, su prometida, antes de haberse casado. Ante esto, Ángelo aplica la ley y condena a muerte a Claudio por el delito de fornicación. Si bien muchos, como Escalus, intentan convencer al juez de que la solución no es la correcta, Ángelo no pone pie atrás.

Nadie duda que Claudio sea culpable. Lo que muchos se cuestionan es otro tema: la aplicación de una ley de forma tan estricta cuando esta ha sido ignorada por más de una década. La interrogante que nos presenta Shakespeare es ¿puede aplicarse una ley dormida por tanto tiempo? En este contexto es relevante considerar que para el derecho romano una ley puede derogarse no solo por un acto del legislador, sino también por el desuso, ya que habría un consentimiento tácito de parte de todos de querer derogarla (Kornstein, 1994: 47; Yoshino, 2011: 68). El gran problema que esto nos presenta es que Claudio al actuar no tenía cómo prever que sus actos serían considerados delito. En cierto sentido, se estaría vulnerando el principio penal de nulla poena sine lege. Para Kornstein este es el principal inconveniente de valerse de una ley luego de su falta de aplicación durante años: no habría advertencia alguna para los posibles afectados (Kornstein, 1994: 48).

Por otra parte, el caso de Claudio y Julieta conlleva otra particularidad: entre ellos hay una promesa de matrimonio que se llevará a cabo próximamente. Para el derecho de la época, ya existe una cierta regulación de su situación jurídica. Si bien el estatus legal de la relación entre Claudio y Julieta es complejo, hay una cuasi relación marital (Posner, 2009: 157). Ante la Iglesia no estarían casados, pero el derecho civil sí suponía que tenían ciertos derechos y obligaciones mutuos y los consideraba casados en cuanto ninguno de los dos era libre de contraer matrimonio con alguien más (Kornstein, 1994: 42). Sin embargo, la ley no incluye esta excepción. El legislador no se ha puesto en el caso de que haya una promesa de matrimonio. Estamos ante un caso difícil. Como muchos han señalado estamos ante la clásica situación: hard cases make bad law (Auden, 2019: 190).

Ángelo, en cambio, no cree conveniente considerar esta particularidad del caso 
ni el hecho que Claudio no pudo prever que se aplicaría la ley que se encontraba dormida. Para Ángelo, Claudio es un ejemplo para el resto de la ciudad; con su muerte quedará claro qué actividades no serán aceptadas en Viena. Bajo esa perspectiva, condenarlo es necesario para el bien moral de la ciudad.

Ante la inminente ejecución de Claudio, su hermana Isabela acude ante Ángelo para pedir misericordia. Isabela es probablemente uno de los personajes más comentados de Shakespeare. Es una mujer atractiva y muy seria. Está a días de consagrarse e ingresar a un convento en una orden especialmente estricta. Isabela sabe que su hermano es culpable del delito que se le acusa, en sus ojos un pecado, pero, a la vez, se da cuenta de que la sanción es excesiva, a fin de cuentas, su hermano y Julieta estaban prontos a casarse. En este sentido, cree que debería hacerse una excepción. Con esta intención acude a Ángelo, quien se niega a modificar su decisión. A la vez, el juez se ha enamorado de ella. Le sugiere que está dispuesto a salvar a Claudio a cambio de su virginidad. Isabela se indigna, se niega a este trato y le dice que la propuesta es inaceptable y que lo acusará por este delito. Ángelo le responde que nadie le creerá, que será su palabra contra la de él y que él es un hombre de excelente reputación.

Desesperanzada Isabela acude donde su hermano para contarle lo ocurrido. Claudio le pide que acepte el trato de Ángelo y ella, una vez más, se niega. En cambio, le sugiere que se prepare para morir. Oculto ha escuchado esta conversación el Duque, disfrazado de fraile Ludovico. El Duque se acerca a Isabela y le propone un plan. Le sugiere que acepte el trato ofrecido por Ángelo, pero bajo la condición de que el encuentro sea en un lugar oscuro. De esta manera, en vez de concurrir Isabela puede acudir Mariana, la mujer con que Ángelo se iba a casar hasta que se entera que, por circunstancias ajenas a su voluntad, se ha perdido su dote. Dado que Ángelo ha incumplido su promesa, descartando a Mariana, y que ella aún está enamorada de él, el Duque sugiere que de esta forma se le obligaría a cumplir su promesa. Hay que recordar que, para el derecho civil de la época, el acto sexual volvía la promesa de matrimonio en un cuasi-matrimonio (Posner, 2009: 157). De esta forma, tampoco se estaría engañando a Ángelo quien estaría simplemente cumpliendo con su promesa, con un contrato que había entrado voluntariamente.

El plan es un éxito excepto por un detalle. A pesar del supuesto sacrificio de Isabela, en realidad Mariana, Ángelo decide de todos modos ejecutar a Claudio. Además, pide que se le envié su cabeza para asegurarse que se haya llevado a cabo su orden. El Duque, aún disfrazado del fraile Ludovico, intenta que el ejecutor demore llevar a cabo la condena de Claudio. Le propone que dé muerte a otro prisionero y le envíe su cabeza. Para suerte de los demás presidiarios, esa noche había fallecido naturalmente un recluso y esa cabeza es enviada a Ángelo. Si bien el Duque ha salvado la vida de Claudio, decide no informarle a Isabela, a quien se le explica que su hermano ha muerto. 
En este contexto, el Duque decide que es hora de volver al poder. Le escribe a Ángelo y Escalus y les señala que deben esperarlo en la puerta de la ciudad para hacer una especie de cambio de mando. Estando en este encuentro, el Duque, ya no disfrazado, sino que vuelto al poder, le pregunta al pueblo si hay alguien que tenga alguna objeción a la forma en que se ha ejercido el poder por Ángelo, si alguno se ha sentido víctima de una actitud injusta. Según las instrucciones del Duque, en ese entonces disfrazado del fraile Ludovico, aparece Isabela y le pide, al propio Duque, que haga justicia. Le explica que han ejecutado a Claudio a pesar de que ella le ha entregado su virginidad a Ángelo para que este no lo matase. El Duque actúa como si no le creyera y la manda a prisión por blasfemar. Aparece Mariana a escena y explica lo que ha sucedido. El Duque actuando como si estuviese molesto, le dice a Ángelo que sea juez de su propia causa, que comience el juicio y abandona el escenario. Vuelve a escena nuevamente disfrazado del fraile Ludovico, y acusa que toda esta situación demuestra la corrupción en Viena. En medio de su explicación su capucha cae y se revela la verdadera identidad del fraile, el propio Duque. Ángelo confiesa su crimen y se auto condena a muerte. El Duque, sin embargo, tiene otros planes. Ángelo se casará con Mariana. Una vez que se haya llevado a cabo la ceremonia será ejecutado por la muerte de Claudio. Ante esto, Mariana desespera y clama por misericordia. Se le une Isabela, quien perdona a Ángelo tanto por la muerte de su hermano como por su acoso e intento de abuso sexual. En este contexto, el Duque hace que traigan a Claudio y explica qué ha sucedido en realidad. Perdona la vida de Ángelo, la de Claudio y le pide a Isabela que se case con él, petición a la que no hay respuesta en la obra.

\section{Tres visiones del derecho y la justicia}

Como ha explicado Kenji Yoshino (2011), ante este caso difícil Shakespeare nos presenta tres prototipos de jueces. En este artículo se propone que el bardo, a través de estos tres modelos de jueces, busca ilustrar distintas visiones del derecho y concepciones de justicia, que llegan a decisiones contrarias de cómo resolver el caso concreto. Desde Ángelo, el supuesto ángel, pasando por el Duque y su solución teatral, a Escalus, cuyo nombre nos recuerda la balanza de la justicia.

\section{a) Ángelo, el supuesto ángel}

Ángelo, el supuesto ángel, condena a Claudio a muerte. Esta decisión responde a una forma específica de entender la interpretación del derecho, el rol de la ley y de la equidad. También corresponde a una manera de comprender la función judicial y expresa una concepción de la justicia.

Ángelo cree en la aplicación estricta de la ley. Su interpretación no permite excepción alguna. El motivo de esto es muy claro: solo una aplicación estricta de la ley 
asegura el respeto al derecho (Kornstein, 1994: 45). En sus palabras:

ANGELO. We must not make a scarecrow of the law,

Setting it up to fear the birds of prey, And let it keep one shape, till custom make it

Their perch and not their terror

(Act 2, scene 1, lines 1-4)

(Shakespeare, 2020, 193)
ANGELO. No podemos convertir la ley en esos espantapájaros

Que se ponen para asustar aves de rapiña

Dejándolos allí inmóviles hasta que la costumbre

Hace de ellos su percha, y no su terror.

(Acto 2, escena 1, líneas 1-4)

(Shakespeare, 2015, 163)

Su preocupación es clara: es urgente proteger el respeto a la ley. No se puede hacer de esta un espantapájaros. Ángelo entiende que la preocupación del Duque de recobrar el cumplimiento del derecho solo puede lograrse a través de la aplicación estricta de la ley. Esta es una decisión consciente de Ángelo, al fin y al cabo, el Duque lo dejó en su lugar, con todos los poderes que necesitara para juzgar.

Ahora bien, en esta concepción del derecho y de la interpretación jurídica hay un aspecto positivo a resaltar: la imparcialidad. Ángelo aclara que su preocupación es que la ley sea perfectamente imparcial. En este sentido, Ángelo es una negación a la arbitrariedad (Kornstein, 1994: 59). No está dispuesto a hacer excepciones porque teme que, al hacerlas, se esté favoreciendo a un individuo por sobre otro. Es por esto que ante la petición de Isabel de que tenga misericordia, Ángelo responde:

ANGELO. I show it most of all when I show justice,

For then I pity those I do not know, Which a dismissed offence would after gall,

And do him right, that answering one foul wrong

Lives not to act another. Be satisfied; Your brother dies tomorrow; be content.

(Act 2, scene 2, lines 104-109)

(Shakespeare, 2020, 224)
ANGELO. Ya lo hago, en exceso, al mostrar mi justicia, apiadándome Así de todos los desconocidos a quienes Una ofensa impune podría corromper. Y soy además justo con aquel que, al pagar

Por su infame delito, no vive para cometer otro. Daos por satisfecha. Vuestro hermano ha de morir mañana. Resignaos.

(Acto 2, escena 2, líneas 105-110)

(Shakespeare, 2015, 189)

Ángelo sinceramente cree que si un juez considera las circunstancias de cada persona y de cada caso habría favoritismo en su decisión. Es por esto que prefiere siempre aplicar la misma vara a todos, incluso a sí mismo. El propio juez debe estar sometido a la ley y ser sancionado de la misma forma que otros individuos son castigados en el mismo caso. De hecho, Ángelo va a llegar al punto de condenarse a muerte, tal como había sentenciado en el caso de Claudio, cuando se descubre que ha cometido el delito de fornicación con quien él creía que era Isabela, pero que en 
realidad era Mariana. Ángelo está dispuesto a llevar su visión del derecho hasta las últimas consecuencias. Como explica Keeton, si bien el Duque lo perdona, y por tanto escapa a la pena, Ángelo termina siendo una víctima de la ley (Keeton, 1968: 371). En realidad, es un mártir de su propia concepción del derecho y de la interpretación judicial.

Esta visión se sustenta en una cierta idea del rol del juez. Ángelo niega que la ley pueda ser ambigua, al contrario, siempre tendrá la respuesta al caso concreto. Por tanto, no hay motivo por el cual el juez tenga que interceder en el caso, basta que aplique la ley. Es por esto que Ángelo termina identificándose con la ley, se vuelve su voz:

ANGELO. (...) I, now the voice of the recorded law (...)

(Act 2, scene 4, line 60)

(Shakespeare, 2020, 244)
ANGELO. (...) Yo, la voz misma de la ley escrita (...)

(Acto 2, escena 2, línea 61)

(Shakespeare, 2015, 205)

Ángelo se adelantó algunos años a Montesquieu: “Ahora bien, los jueces de la nación no son, según sabemos, sino la boca por donde habla la ley, seres inanimados que no pueden moderar ni su fuerza ni su rigor" (Montesquieu, 1906: 237). Tanto el filósofo como el personaje restringen la labor judicial. Ángelo no se ve a sí mismo como un guionista, no cree que tiene control sobre sus propias sentencias (Gulley, 1996: 59). Es la ley, y solo la ley, la que toma la decisión. Esta debe ser aplicada en sus propios términos, y no debe ser evaluada a través de otros parámetros, como la moral. Siguiendo la idea de Ronald Dworkin de la novela legal en serie (Dworkin, 2012), Ángelo recibe la novela, pero se niega a verse a sí mismo como autor de su capítulo. El único autor posible es la ley. Para el juez, la necesidad de una justicia estricta e imparcial solo puede darla la ley, no la actuación judicial. En cierto sentido, Ángelo renuncia a ejercer la labor judicial.

ANGELO. It is the law, not I, condemn your brother.

Were he my kinsman, brother, or my son,

It should be thus with him: he must die tomorrow.

(Act 2, scene 2, lines 84-86)

(Shakespeare, 2020, 221-222)
ANGELO. Es la ley quien condena a vuestro hermano, no yo.

Fuera él mi pariente, mi hermano, mi hijo,

Y nada me haría cambiar. Debe morir mañana.

(Acto 2, escena 2, 84-86)

(Shakespeare, 2015, 189)

La visión de Ángelo de la labor judicial, su noción de derecho y la forma en que entiende el rol de la ley, responden a una cierta concepción de justicia: todos los casos deben ser tratados de igual forma. Para esto, el criterio debe ser constante y parejo para todos; solo la regla jurídica escrita es capaz de hacer esto. De esta forma, la concepción de justicia de Ángelo es severa e imparcial, pero a la vez, no le da espacio 
a la piedad, parcialidad o consideración de circunstancias atenuantes. Es una justicia acorde a la ley (Keeton, 1968: 384). Es por esto que es posible concluir que Ángelo pertenece a la tradición de la justicia ciega (Kornstein, 1994: 59).

A la vez, esta concepción de la justicia como imparcialidad está traspasada por la corrupción del juez. El no tan angelical Ángelo, el que cree en la aplicación estricta de la ley, se envenena de poder y se corrompe. Utiliza su posición de poder para ofrecerle a Isabela un trato reprochable: está dispuesto a absolver a Claudio si Isabela le entrega su virginidad. La propuesta conlleva el mismo delito por el cual Claudio está condenado a muerte: fornicación. Hay, eso sí, una diferencia importante. En el caso de Claudio hay un consentimiento libre de ambas partes y una promesa de matrimonio. En cambio, en el caso de Ángelo, de aceptar Isabela, no hay consentimiento libre, sino que una violación. Es por esto que hay una cierta superioridad moral en el caso de Claudio por sobre el de Ángelo (Goddard, 1960: 53).

Ahora, es importante señalar que Ángelo no es un villano por naturaleza, sino que se vuelve un tirano. Para Goddard, el protagonista de la obra es uno de los estudios más potentes que se han hecho sobre el efecto del poder en una persona. Ángelo no era un villano o un tirano, a pesar de cómo trató a Mariana (Goddard, 1960: 50; Kornstein, 1994: 54). Sin embargo, se volverá uno al intentar utilizar su poder para su beneficio personal.

ISABELLA. (...) 0, it is excellent To have a giant's strength, but it is tyrannous

To use it like a giant.

(Act 2, scene 2, lines 111-113)

(Shakespeare, 2020, 224-225)
ISABELLA. (...) Cuán maravilloso debe Ser tener la fuerza de un gigante y cuán tiránico -Como gigante- usarla.

(Acto 2, escena 2, líneas 111-113)

(Shakespeare, 2015, 189-191)

Entonces, podemos ver un segundo caso en la obra, el de Isabela versus Ángelo. Ahora bien, es importante destacar que incluso en este caso para Ángelo la labor judicial seguirá siendo la aplicación estricta de la ley. Si bien de forma imparcial el Duque le pide a Ángelo que sea juez de su propia causa, el juez-parte va a fallar en su contra, sentenciándose a muerte al igual que el caso decidido anteriormente, el de Claudio. Ángelo si bien no puede ser totalmente imparcial, si seguirá actuando como la boca de la ley.

\section{b) El Duque y la solución teatral}

Si Ángelo peca de un exceso de estrictez y legalismo, el Duque falla en su demasía de laxitud. La misericordia del Duque lo lleva a un relajo absoluto en su función judicial que termina constituyendo también una renuncia a su autoridad.

El Duque ha fallado durante los últimos catorce años. Como ya se ha explicado, en Medida por Medida se presenta a Viena como una ciudad que ha perdido su norte 
moral, en la cual los niños golpean a sus nodrizas. En las obras de Shakespeare la antítesis entre orden y caos se encuentra siempre presente. En el caso de las tragedias, el caos se expresa en el quiebre del sistema jurídico (Jocelyn-Holt, 2017), mientras que en las comedias nos encontramos ante el carnaval, en donde, por una cantidad de tiempo determinado, los roles se invierten y la aplicación de la ley es interrumpida. En el caso de Medida por Medida, el carnaval es responsabilidad directa del Duque, quien es el autor de la no aplicación de las leyes durante la última década. Por otra parte, si el Duque consideraba que la ley era excesivamente estricta y es por esto que no quiere aplicarla, es crucial preguntarse por qué no la modificó (Yoshino, 2011: 64). Al fin y al cabo, el Duque es el único poder legislativo posible en Viena (Jordan, 2013: 104). Si bien la obra asume que las reglas son inmutables, desde un punto de vista jurídico sabemos que el Duque o fue quien creó dichas normas, o bien no las modificó o derogó teniendo la posibilidad de hacerlo. De esta forma, tanto por acción como por omisión, el Duque es el único responsable del carnaval. Gran parte de esa responsabilidad recae en no acudir a la institución del derecho, sea ignorándola como juez, como evitándola como legislador. En el fondo, mientras Ángelo idealiza en demasía la letra de la ley, el Duque no cree en el derecho. En cambio, opta por el teatro, o como sugiere Gulley, teatraliza al derecho (Gulley, 1996).

Ante el carnaval, el Duque prefiere seguir los consejos de Maquiavelo (Jordan, 2013: 101-102). En vez de hacerse responsable y actuar como el juez que es, prefiere dejar su poder a Ángelo y mover la trama desde las sombras. Es posible sostener que el Duque sabe perfectamente que dejando a Ángelo en su lugar puede crear una situación sumamente complicada. Tiene conocimientos e información que le hacen al menos sospechar. Al fin y al cabo, sabe lo que ha hecho con Mariana. Pudo haber dejado a Escalus en su lugar, alguien que tenía mayor experiencia y que no tenía un pasado manchado. En este sentido, el Duque lleva a cabo un experimento. Más que preocuparse por el estado de Viena, ha decidido utilizar a alguien que él sospecha que puede fallar erradamente, para luego volver en gloria y majestad.

Duke: (...) Lord Angelo is precise,

Stands at a guard with envy, scarce confesses

That his blood flows, or that his appetite

Is more to bread than stone. Hence shall we see,

If power change purpose, what our seemers be.

(Act 1, scene 3, lines 50-55)

(Shakespeare, 2020, 184)
DUQUE. (...) Lord Angelo es persona escrupulosa,

Alerta ante la envidia, apenas revela que la sangre

Corra por sus venas, o que su apetito

Sea de pan más que de piedra. Este es momento de comprobar

Si el poder justifica el fin: o si es pura apariencia.

(Acto 1, escena 4, líneas 50-54) (Shakespeare, 2015, 153) 
Si bien es posible interpretar estas líneas como que el Duque quiere ver qué pasará en la ciudad y en los individuos una vez que el poder cambie de manos a alguien más estricto, no es menos cierto que es posible leer en sus palabras una segunda intención: el Duque quiere probar cuál será el comportamiento de su segundo a cargo.

En este sentido, este artículo se aleja de aquellas interpretaciones que consideran al Duque como un personaje que llama a la moderación al juzgar. Esta lectura propone que si bien este ha renunciado a sus responsabilidades, desde las sombras actúa como un juez; escucha a los personajes y testigos involucrados y de esta manera se informa para luego al final de la obra presentar una solución razonable (Rackley, 2008: 74). Muy al contrario, este artículo propone que el Duque permanentemente se niega a juzgar y asumir la responsabilidad que esto conlleva. Prefiere el teatro, desde las sombras construye su trama e intenta manipular las situaciones como un director. El teatro del Duque es manipulación, al menos en el caso de Isabela (Bloom, 1998: 371). Esto es lo único que explicaría por qué toma la cruel decisión de no decirle que su hermano está vivo. No hay ningún motivo por la aplicación de justicia que justifique mentirle con un hecho tan doloroso para ella. Es por esto que el Duque puede recordarnos a Hamlet, ya que monta una obra dentro de la obra (Goddard, 1960: 52).

También en este sentido, y siguiendo a Posner, habría un paralelo entre el Duque en Medida por Medida y Porcia en El Mercader de Venecia. Ambos se disfrazan e intentan modificar los hechos para su propia conveniencia (Posner, 2009: 158). Porcia, una mujer que imposta a un doctor en derecho engañando al sistema de adjudicación de justicia, que actúa sin investidura regular, con conflicto de interés y que incentiva la crisis para poder encontrar una salida teatral al problema, ignorando las salidas jurídicas más directas y obvias, obstruyendo el sentido del derecho (Jocelyn-Holt, 2017: 220-224), nos recuerda mucho al Duque de Viena. El Duque que imposta a un fraile engañando al sistema de creencia y confianza personal entre un individuo y un creyente (no hay que olvidar que toma confesiones), que en el fondo no tiene investidura regular de clérigo, que tiene un conflicto de interés en el éxito o fracaso de Ángelo (al fin y al cabo según cuan exitoso sea este, como podrá volver el Duque en gloria y majestad), que incentiva la crisis para poder resolverla teatralmente y como héroe de la ciudad, y que también evade las salidas jurídicas más obvias tales como la reforma de la ley, privilegiando el teatro por sobre el derecho. En este sentido, todo lo que se puede decir de Porcia es aplicable al Duque.

En ese contexto resulta crucial analizar el final de la obra, el último acto, en el que el Duque finalmente actúa como juez. En el que decide y soluciona el conflicto. Recordemos cuáles son sus sentencias. En primer lugar, resolviendo el caso de Isabela y Mariana versus Ángelo, decide que el supuesto ángel se casará con Mariana. Luego de esto será ejecutado. Después de que Isabela pide clemencia por él, el Duque le 
perdona la vida, pero mantiene la obligación matrimonial. En el caso que ha iniciado todos los problemas, el de Viena versus Claudio, el Duque también le perdona la vida y nuevamente ordena un matrimonio, el de Julia con Claudio. Por último, y casi como si fuese un premio por sus actos, le propone matrimonio a Isabela.

Entender esta escena es clave para poder dar una opinión definitiva sobre el Duque y sus actos. Para algunos críticos shakesperianos, lo que el fallo del Duque demostraría es que la ley y la justicia deben ser temperadas con misericordia (Keeton, 1968: 381). Para otros optimistas, luego del caso de Claudio, que ha sido tan excepcional y complicado, la justicia en Viena no volverá a ser la misma. La excesiva laxitud del Duque y la rigidez de Ángelo, han sido reemplazadas por una visión de la justicia como conversación y relación. La salida de Ángelo ha demostrado ser errada, la del Duque morigerada por su experiencia como fraile (Rackley, 2008: 78).

Este artículo es más pesimista. Se propone que el Duque una vez más erra. Durante catorce años no ha sabido aplicar la justicia correctamente, y nuevamente comete los mismos errores. La decadente Viena seguirá siendo decadente y el derecho seguirá siendo un espantapájaros.

Lo que hace el Duque es ignorar totalmente la ley en cada uno de los casos que tiene al frente. No es que haya decidido perdonar a todos, al contrario, de una u otra manera muchos de los personajes son castigados. Las sentencias del Duque son punitivas, no hay duda de esto. Ángelo es humillado y forzado a auto condenarse. Además, es penado a casarse con una mujer que ya ha rechazado. Lo mismo en el caso de las sentencias menores del Duque, como la de Lucio, hombre que había hablado en contra de él al propio fraile del cual estaba disfrazado, es obligado a casarse con una mujer a la que no quiere ni respeta pero que ha dejado embarazada. Incluso, se ha llegado a concluir que la propia Isabela es castigada por rechazar su propia sexualidad con una propuesta de matrimonio cuando ella lo único que quiere es entrar al convento (Visconsi, 2011: 286).

Por otra parte, el personaje al que el Duque debió haber castigado es, en cambio, perdonado. Barnardine es un hombre condenado a muerte hace años cuya sentencia nunca ha sido ejecutada. Estuvo a punto de serla para tomar el lugar de Claudio y poder enviar su cabeza a Ángelo. En ese momento, fue la suerte que lo acompañó, ya que murió naturalmente un prisionero que se parecía a Claudio y que podía tomar su lugar. Barnadine es un personaje que si bien puede pasar desapercibido es central para la obra. Según Harold Bloom, este es el personaje más interesante de la historia, el personaje más peculiar de los dramas de Shakespeare. En lo que respecta al sistema jurídico, Barnadine no sigue las reglas de Viena; tampoco le interesa su misericordia (Bloom, 1998, 374-380). Cuando se le busca para ejecutarlo simplemente se niega. Tampoco le importa qué resultará de su situación, con tal de poder seguir alcoholizándose. Asimismo, se niega a cooperar con el derecho. De todas formas, el Duque lo absuelve y le permite volver a ser libre por las calles de Viena. De 
todos los criminales que vemos en la obra, este es el único realmente perdonado.

La única sentencia que puede ser aprobada por el público es la del caso que provocó la obra: al fin y al cabo, Claudio es perdonado y su matrimonio con Julieta parece natural. Sin embargo, es una solución que no se encuentra en la ley. No es que Claudio sea absuelto, es que su pena es reemplazada por una obligación de matrimonio con Julieta. Al igual que en el caso de Ángelo, y en el de Lucio, las tres condenas de muerte son sustituidas por matrimonios, el cual es presentado con un sentido punitivo. La diferencia en el caso de Claudio es que este matrimonio es deseado por las partes (Auden, 2019: 191). Si bien Shakespeare suele recurrir a matrimonios al final de las comedias, lo hace para consolidar relaciones amorosas ya establecidas. Así, por ejemplo, en Sueño de una Noche de Verano, los matrimonios del último acto no solo resuelven el problema de identidades que existió durante la obra, además institucionalizan jurídicamente las relaciones amorosas ya existentes. Es así como los matrimonios suelen ser parte de finales felices. En cambio, en Medida por Medida son utilizados de forma punitiva. Entonces no debería sorprendernos la sensación de que al final de la obra no hay justicia. (Aristodemou, 2000: 92; Visconsi, 2011: 286)

Así el Duque se salta la ley. En cierto sentido solo aplica lo que él cree que es el espíritu de la ley. Si la aplicación de justicia fuera un péndulo, en un lado encontraríamos a Ángelo, la pura letra de la ley, y en el otro al Duque, solamente el supuesto espíritu de esta. Ahora bien, como hay una cierta equivalencia entre la ley y el Duque, es posible argumentar que lo que se aplica en este final es el espíritu del Duque a través del teatro por sobre el derecho.

Es posible argumentar que esta visión de la labor judicial también se encuentra traspasada por la discusión de la corrupción. Si bien de una forma diferente a la de Ángelo, el Duque también es corrupto. En vez de solucionar el problema sigue el consejo de Maquiavelo en El Príncipe, renuncia a su posición política para que alguien más, Ángelo, le arregle la situación, se lleve la culpa y él pueda volver a una Viena ordenada (Posner, 2009: 158-159). En este contexto, y como explica Keeton, el Duque abdica de sus responsabilidades sin una buena causa (Keeton, 1968: 371). Peor aun, ha hecho de esta situación un juego, eligiendo a Ángelo por sobre Escalus, sabiendo que el primero no tiene el mejor perfil para ello.

En este contexto, es relevante resaltar que la abdicación del Duque de sus responsabilidades, su deber de juzgar y de imponer orden en Viena, es claramente central para Shakespeare. Hay que recordar que el bardo no solía inventar sus tramas, sino que recontaba historias que ya habían sido escritas. Sin embargo, siempre hace ciertas modificaciones. A estas hay que ponerle especial atención. En el caso de Medida por Medida, Shakespeare nos recuenta la historia de Promos y Cassandra, la cual, a su vez, había sido transformada en tragedia por Cinthio en Epitia. Una de las modificaciones más claras de Shakespeare es que en la versión de Cinthio el Duque no abdica de su rol, sino que simplemente revisa el caso como un órgano de apelación 
(Keeton, 1968: 372-373). Por tanto, la preocupación shakesperiana no recae en lo que pareciera más obvio, lo importante que es que exista la apelación y que el caso de Claudio pueda ser revisado, sino que en el caos que lleva consigo la abdicación del rol judicial.

Así es como empezamos a ver en Medida por Medida la aparición de la idea de que nada es lo que parece (Jordan, 2013: 114). Es la misma temática que ya vimos en El Mercader de Venecia (Jocelyn-Holt, 2017: 217-232). El Duque no es necesariamente el héroe que salva el día y a la ciudad del error de Ángelo, sino que quizás es la fuente de todos los problemas en Viena. Al fin y al cabo, si el Duque hubiese aplicado la ley cuando correspondía y no hubiese salido arrancando de enfrentar su responsabilidad como juez, la vida de Claudio jamás habría estado en peligro.

De esta forma, el Duque nos muestra una aproximación al derecho totalmente diferente a la de Ángelo. A su vez, su concepción de la justicia es también radicalmente distinta. La preocupación del Duque no es tratar todos los casos de la misma forma, sino que analizar en exceso las circunstancias especiales de cada caso, aun sobre la ley. Es por esto que esta concepción cae fácilmente en la arbitrariedad a la que Ángelo le tenía tanto temor.

\section{c) Escalus y la balanza de la justicia}

Como ya hemos visto, los dos modelos de jueces más notorios en la obra son Ángelo y el Duque. Sin embargo, ambos son corruptos y no logran llegar a soluciones óptimas para concretar la justicia. ¿Significa esto que Shakespeare se desilusiona del derecho al escribir Medida por Medida? Sería extraño, ya que después el dramaturgo probablemente se concentraría en escribir Otelo y El Rey Lear, dos tragedias en que hay una apuesta por el derecho (Jocelyn-Holt, 2017). En realidad, lo que hace el bardo es mostrarnos una salida, la cual pasa desapercibida en la obra. Son dos los personajes en que hay que poner atención para encontrarla: Isabela y Escalus.

Comencemos con Isabela, la cuasi-monja que ruega por su hermano. Este ha sido uno de los personajes más estudiados de la obra, y ciertamente uno de los más reprochados por los críticos en el canon shakesperiano. Se le reprende no haberse sacrificado para salvar a su hermano y se le regaña por su visión algo conservadora y estricta de la vida y de la sexualidad. Solo recientemente la crítica feminista ha reinterpretado su rol (Aristodemou, 2000: 81-104).

En lo que atañe a la propuesta jurídica de Shakespeare, Isabela nos ilustra una visión distinta a la del Duque y Ángelo (Tasioulas and Tasioulas, 2013: 227-229). Isabela es un personaje que sí mantiene el espíritu del derecho a la vez que acata la letra de la ley. Junto a Escalus serán los únicos personajes que respetan el derecho, en una sociedad en que la ley es despreciada y constantemente desacatada (Rackley, 2008: 78). Isabela sabe que su hermano es culpable del delito que se le acusa. Es más, 
para ella lo que ha hecho su hermano es sumamente reprochable, no solo un delito, sino que también un pecado. Es por esto que no va a implorar por su absolución dada una falsa inocencia. Por otra parte, Isabela también sabe que la ley puede considerar ciertas circunstancias particulares del caso y, de ser necesario, se puede acudir a la equidad. Al saber del delito de su hermano, responde "0, let him marry her" (Act 1, scene 4, line 48) “DDeberían casarse ya!” (Acto 1, escena 5, línea 48). Esto es lo que le pide a Ángelo, que respete la ley, pero a la vez que comprenda las particularidades, que tenga misericordia y perdone a Claudio. Isabela va a reiterar esta misma perspectiva del derecho y la aplicación de justicia en su caso contra Ángelo. Al fin y al cabo, lo perdona tanto por intentar abusar de ella como por la supuesta muerte de su hermano.

Si bien la visión del derecho de Isabela es relevante, aunque pasa desapercibida en una primera lectura de la obra, hay que tener en consideración que en ningún momento ella actúa como jueza, al contrario, siempre es la víctima de las decisiones de jueces. Sin embargo, en Medida por Medida hay un juez que tiene la misma noción del derecho y la aplicación de la justicia que ella: Escalus.

Escalus ha sido especialmente destacado como el modelo de juez por muchos de los autores que han estudiado Medida por Medida desde la perspectiva del derecho y la literatura (Kornstein, 1994: 61; Yoshino, 2011: 62, 80-83; Bevington, 2013: 164). Si bien es un juez que en una primera lectura puede pasar desapercibido, Shakespeare nos da una serie de pistas que deberían ayudar a llamar nuestra atención. La primera es la descripción que el Duque hace de Escalus. En la primera escena, y antes de dejar el poder, el Duque habla sobre Escalus en los mejores términos: tiene conocimiento técnico, probidad moral y conoce los términos de la justicia. Si bien por motivos inexplicables no lo deja a cargo de Viena, el público es introducido a un personaje que debiese tener en alta estima.

En segundo lugar, y esta es una pista que suele pasar desapercibida, uno de los asesores de Escalus es Justice, literalmente la justicia. Este personaje tiene un rol limitado, y muy pocas líneas, aunque habría que destacar "Lord Angelo is severe" (Act 2, scene 1, line 271) "Lord Angelo es inflexible" (Acto 2, escena 1, línea 269). Si bien es cierto que es un personaje muy menor, no deja de ser llamativo que Escalus falle sus casos con Justice (la justicia) a su lado.

La tercera pista de Shakespeare es el nombre que le ha elegido a su personaje. Como ha argumentado Yoshino, el nombre Escalus significa balanza y nos debería recordar rápidamente a la balanza que la figura de la justicia lleva en su mano (Yoshino, 2011: 62). También esta imagen la podemos asociar con alguien mesurado, un punto medio, que es capaz de balancear por un lado la letra de la ley y por otro el espíritu del derecho. En este sentido, Escalus es presentado como un equilibrio entre Ángelo y el Duque.

La balanza de Escalus puede ser claramente vista en los casos que resuelve. 
Luego de que Ángelo ha cerrado los prostíbulos de Viena empiezan a llegarle algunos asuntos en ese respecto. El alguacil de Viena, Elbow, trae ante ellos a Froth y Pompey, quienes han sido descubiertos incumpliendo con la regulación sobre prostitución que Ángelo ha hecho efectiva. Uno trabaja para Mistress Overtone, dueña de uno de los prostíbulos que deberían haber cerrado, mientras que el otro es un cliente frecuente. A Ángelo le parece que este es un caso menor y de poco interés, por lo que prefiere dejárselo a Escalus, señalándole que espera que pueda azotarlos a todos. Es aquí cuando vemos al juez mesurado actuando. Escalus escucha a todas las partes y deja a Pompey y a Froth libres, eso sí, les da una advertencia de que no quiere que continúen con este comportamiento y que espera no volver a verlos, y que si incumplen las normas tendrá que castigarlos y azotarlos. En el fondo, Escalus sabe que al aplicar una ley que ha estado dormida, debe, antes de hacer andar el aparato punitivo, dar una prevención a los individuos de que esta regulación será utilizada nuevamente. Por tanto, reconoce la importancia del reconocimiento de las distintas circunstancias en la aplicación del derecho. De esta forma, Escalus respeta la letra de la ley, pero la equilibra con el espíritu del derecho. Sin embargo, cuando se entera de que se ha seguido incumpliendo la ley, Escalus la aplica, a pesar de los ruegos de Mistress Overtone.

ESCALUS. Go, away with her to prison. OVERDONE. Good my lord, be good to me, your honour is accounted a merciful man, good my lord -

ESCALUS. Double and treble admonition, and still forfeit in the same kind? This would make mercy swear and play the tyrant.

(Act 3, scene 1, lines 448-453)

(Shakespeare, 2020, 283)
ESCALUS. Adelante, que la lleven a prisión.

MADAM. Señor, apiadaos de mí. Vos tenéis fama de hombre justo, mi buen señor.

ESCALUS. ¿Dos, tres veces amonestada y todavía reincidiendo en lo mismo? Hasta la clemencia protestaría por eso, y se tornaría tirana.

(Acto 3, escena 1, líneas 455-460) (Shakespeare, 2015, 245-247)

A diferencia del Duque, Escalus sabe que la misericordia tiene un rol delimitado en el derecho. Hay un momento en que la ley debe aplicarse. De esta forma, Escalus balancea el espíritu del derecho con la aplicación de la ley. Por otra parte, esta pareciera ser la estrategia a llevar a cabo para disminuir el carnaval en Viena. Como explica Bevington, mientras la obra avanza es posible ver cómo la aproximación de Escalus reduce la conducta licenciosa en Viena (Bevington, 2013: 169).

Como hemos explicado, la aproximación de Escalus a la labor judicial es un punto medio entre los excesos de Ángelo y del Duque. Para Yoshino, Escalus impone una noción de proporcionalidad en el derecho. Busca una solución intermedia entre la aplicación estricta de la ley y la no aplicación del derecho. Aplica discrecionalidad, 
pero dentro del imperio del derecho (Yoshino, 2011: 81). Es así como, por un lado, respeta la letra de la ley, pero, a diferencia de Ángelo, sí cree que las particularidades de un caso deben ser consideradas. Por otra parte, si bien entiende la importancia que las circunstancias pueden tener en el derecho $\mathrm{y}$, tal como el Duque, cree en la misericordia (Keeton, 1968: 388), se diferencia de este en que es sensible a las repercusiones que el perdón puede tener (Tasioulas and Tasioulas, 2013: 225). En este sentido, de todos los jueces que vemos en la obra, Escalus es el único que realmente aplica equidad como una forma institucionalizada de la misericordia. Escalus, a diferencia del Duque, no sale del derecho para resolver los casos difíciles. Como explica Graver, Escalus limita el lugar de la misericordia a su contexto jurídico, la equidad, en la cual se toma en cuenta a la persona que actúa y no solamente si las circunstancias corresponden a los hechos fácticos de una norma jurídica (Graver, 2012: 161). Esta sería la definición del imperio del derecho de Escalus, como una relación entre los hechos particulares del caso y los principios generales del derecho en que la ley se funda (Gulley, 1996: 58).

En cierto sentido Medida por Medida tiene elementos trágicos en las figuras de los jueces. El que pudo haber solucionado el caso difícil en la obra es el único que no tiene la oportunidad de hacerlo. Escalus es el juez que pudo haber sido, pero que no fue. Es el juez que el público se imagina que pudo aplicar equidad y haber solucionado el tema. De hecho, Escalus le hace la misma prevención al Duque que Isabela le hará en unas escenas después: que se ponga en la situación de Claudio, y que el que esté libre de pecado lance la primera piedra. Al discurso de Ángelo de que no hay que hacer un espantapájaros del derecho, Escalus responde:

ESCALUS. Ay, but yet

Let us be keen, and rather cut a little

Than fall and bruise to death. Alas, this gentleman

Whom I would save had a most noble father.

Let but your honour know, Whom I believe to be most strait in virtue,

That in the working of your own affections,

Had time cohered with place, or place with wishing,

Or that the resolute acting of your blood

Could have attained th' effect of your own purpose,

Whether you had not sometime in your life

Erred in this point which now you
ESCALUS. Así es.

¿Pero acaso sea mejor hacer un corte somero

Que ir al fondo hiriendo a muerte?

Notad, señor,

Que este caballero a quien quisiera yo salvar tenía

Un muy noble padre. Pero decidme señoría,

(Y muy bien conozco vuestra virtud), Que tanto en el caso del devenir de vuestros afectos,

Siendo el tiempo preciso con el lugar y

el lugar preciso con el deseo,

Como en el caso del bullir de vuestra sangre,

¿No habríais juntado deseo y objeto por interés vuestro?

¿No os ha sucedido - tan solo una vez en 
censure him

And pulled the law upon you.

(Act 2, scene 1, line 4-16)

(Shakespeare, 2020, 193-194) la vida-

Que hayáis errado hasta el punto que ahora le censuráis a él, $\mathrm{Y}$ que pone la ley en contra vuestra?

(Acto 2, escena 1, líneas 4-16)

(Shakespeare, 2015, 163)

De esta forma, Escalus no solo ha prevenido a Ángelo, sino que también ha informado al público que él habría fallado de forma completamente diferente. Él habría dejado libre a Claudio. De hecho, le pide a Ángelo que en el caso de Claudio se tempere el rigor de la ley, pero Ángelo no acepta. Al parecer, también le ha insistido en varias otras ocasiones.

ESCALUS. (...) I have laboured for the poor gentleman to the extremest shore of my modesty, but my brother justice have I found so severe that he has forced me to tell him, he is indeed Justice.

(Act 3, scene 1, lines 507-511) (Shakespeare, 2020, 286-287)
ESCALUS. (...) Me he esforzado por interceder hasta la orilla misma de la discreción, hasta el punto de obligarme a decir a mi hermano -todo justiciaque de tan severo, él es la propia Justicia

(Acto 3, escena 1, líneas 513-517)

(Shakespeare, 2015, 249-251)

De esta forma, Shakespeare nos ha presentado una alternativa viable, una noción de derecho y de la aplicación de justicia que considera la proporcionalidad y la misericordia, a la vez que respeta el imperio del derecho. Es una tercera vía, una tercera concepción de justicia.

\section{Conclusión}

William Shakespeare en Medida por Medida, una de sus obras jurídicas, se pregunta por la naturaleza del derecho y su relación con la justicia. En esta comediaproblema nos presenta tres visiones del derecho, que conllevan tres modelos de jueces y tres concepciones de la justicia. Para hacer esto, el bardo nos presenta un caso difícil y tres jueces con miradas distintas del derecho, del rol judicial y de la justicia, que impactan en diversas maneras de resolver el caso concreto.

En primer lugar, Shakespeare nos presenta a Ángelo, el supuesto ángel. En él vemos representada el concepto de la aplicación estricta de la ley como la forma de asegurar el respeto al derecho. Esta idea lleva consigo una noción de imparcialidad del juez como una negación a la arbitrariedad. En este contexto, el juez no tiene ningún rol relevante, sino que es transformado en la boca de la ley. En cierto sentido, habría una renuncia a la labor judicial. Este concepto de derecho está aparejado a una forma de entender la justicia como el deber de tratar todos los casos de la misma forma. Sin embargo, no se consideran las circunstancias atenuantes que pudiesen modificar una 
aplicación irrestricta de la ley. La idea de justicia se vuelve sinónima a la de la aplicación de la ley. A su vez, Shakespeare también nos ilustra un problema que esta teoría no soluciona: los efectos de que el juez se vuelva tiránico, poniendo en tela de juicio la imparcialidad.

Al otro lado del péndulo encontramos al Duque. En él hemos visto cómo su misericordia entendida como una no aplicación de la ley, ha llevado al carnaval y a la renuncia a ejercer la autoridad. En este contexto este artículo ha argumentado que el Duque en realidad no cree en el derecho, ignora la ley y prefiere optar por el teatro. Como juez, aplica lo que él cree que es el espíritu de la ley. Sin embargo, dado que la ley en Viena es el propio Duque, en realidad aplica el espíritu del Duque a través del teatro por sobre el derecho. Más aun, el Duque es en cierto sentido un corrupto. Ha renunciado a su obligación de juzgar e imponer orden, lo que ha traído consigo el caos. Incluso, al negarse a actuar como juez, y al renunciar a sus obligaciones, ha sido él quien ha puesto la vida de Claudio en peligro. De esta forma, Shakespeare nos muestra cómo el exceso de misericordia, a la vez que ignorar al derecho, lleva a la arbitrariedad. No nos debería entonces sorprender que las soluciones del Duque no son a largo plazo. Es claro que al caer el telón Viena seguirá siendo un carnaval y la ley un simple espantapájaros.

De esta forma, es claro que ni Ángelo ni el Duque logran la justicia. Ante este problema se ha propuesto que Shakespeare se habría decepcionado del derecho en esta obra. Este artículo ha planteado que esto no es así, Shakespeare mantiene su apuesta por el derecho, la cual se encuentra en una tercera visión del derecho, una nueva interpretación del rol judicial y de la concepción de la justicia. Esta idea se encuentra en Isabela y especialmente en Escalus, la balanza, en donde vemos un juez que es capaz de mantener el espíritu del derecho a la vez que el respeto a la ley. Esto significaría, en el caso de Claudio, la consideración de las circunstancias particulares que requerirían morigerar la letra de la ley. De esta forma, la misericordia es institucionalizada dentro del derecho y expresada a través de la equidad. Shakespeare nos presenta su propia visión del derecho, del rol de la aplicación de justicia y su concepción de la justicia: la balanza.

\section{Bibliografía}

Aristodemou, M. (2000): Law and Literature. Journeys from Her to Eternity. Oxford, Oxford University Press.

Auden, W.H. (2019): Lectures on Shakespeare. New Jersey, Princeton University Press.

Bevington, D. (2013): "Equity in Measure for Measure", en B. Cormack, M. Nussbaum y R. Strier, eds., Shakespeare and the Law. A Conversation Among Disciplines and 
Professions. Chicago y Londres, The University of Chicago Press, 164-173.

Bloom, H. (1998): Shakespeare. The invention of the human. New York, Riverhead Books.

Dworkin, R. (2012): Law's Empire. Oxford, Hart Publishing.

Fuller, L.L. (2002): El caso de los exploradores de cavernas. Traducción de G.R. Carrió and L.J. Niilus. Buenos Aires, Lexis Nexis Abeledo-Perrot.

Goddard, H.C. (1960): The Meaning of Shakespeare. Chicago, The University of Chicago Press.

Graver, H.P. (2012): "Measure for Measure: On Law and Forgiveness", en H. Porsdam y T. Elholm, eds., Dialogues on Justice. European Perspectives on Law and Humanities. Alemania, De Gruyter, 160-174.

Gulley, E. (1996): "'Dressed in a little brief authority': Law as Theater in Measure for Measure", en B.L. Rockwook, ed., Law and Literature Perspectives. New York, Peter Lang Publishing, 53-80.

Jocelyn-Holt, E. (2017): Del Caos al Imperio del Derecho. La búsqueda de la justicia en Shakespeare. Santiago de Chile, Rubicón Editores.

Jordan, C. (2013): "Interpreting Statute in Measure for Measure", en B. Cormack, M. Nussbaum, y R. Strier, eds., Shakespeare and the Law. A Conversation Among Disciplines and Professions. Chicago y Londres, The University of Chicago Press, 101-120.

Keeton, G.W. (1968): Shakespeare's Legal and Political Background. New York, Barnes \& Noble Inc.

Kornstein, D. (1994): Kill all the lawyers? Shakespeare's legal appeal. Lincoln, Princeton University Press.

Montesquieu (1906): El Espíritu de las Leyes. Madrid, Librería General de Victoriano Suárez.

Posner, R. (2009): Law and Literature. Cambridge, Harvard University Press.

Rackley, E. (2008): "Judging Isabella: Justice, Care and Relationships in Measure for Measure", en P. Raffield y G. Watt, eds., Shakespeare and the Law. Oxford y Portland, Hart Publishing.

Shakespeare, W. (2015): Medyda, Por Medida. Madrid, Catedra (Letras Universales). 
Shakespeare, W. (2020): Measure for Measure. Londres y New York, Bloomsbury Publishing (The Arden Shakespeare).

Tasioulas, J. y J. Tasioulas (2013): "'Lawful Mercy' in Measure for Measure", en J. Keown y R.P. George, eds., Reason, Morality, and Law. The Philosophy od John Finnis. Oxford, Oxford University Press, 219-235.

Visconsi, E. (2011): 'Measure for Measure: No Remedy', en A. Sarat, C. O. Frank y M. Anderson, eds., Teaching Law and Literature. New York, The Modern Language Association of America, 279-287.

Yoshino, K. (2011): A Thousand Times More Fair. What Shakespeare's Plays Teach us About Justice. New York, Harper Collins Publishers.

Fecha de recepción: 31 de julio de 2021

Fecha de aceptación: 10 de noviembre de 2021 